\title{
Beneficial effect of chronic Staphylococcus aureus infection in a model of multiple sclerosis is mediated through the secretion of extracellular adherence protein
}

\author{
Prateek Kumar ${ }^{1}$, Benedikt Kretzschmar ${ }^{1}$, Sabine Herold ${ }^{1}$, Roland Nau², Mario Kreutzfeldt ${ }^{3}$, Sandra Schütze ${ }^{2}$, \\ Mathias Bähr ${ }^{1}$ and Katharina Hein ${ }^{1 *}$
}

\begin{abstract}
Background: Bacterial infections have been assumed to worsen multiple sclerosis (MS) disease symptoms and to lead to increased neurodegeneration. However, the underlying biological mechanisms for these effects are complex and poorly understood. Here, we assessed the disease-modulating effects of chronic infection with Staphylococcus aureus, a common human pathogen, on the clinical course and the extent of neurodegeneration in experimental autoimmune encephalomyelitis (EAE), an animal model of MS.

Methods: To conduct this study, we established a persistent chronic infection in female brown Norway rats by inoculating Staphylococcus aureus (S. aureus) bacteria in a subcutaneously implanted tissue cages.

Results: In this study, we observed that the introduction of a localized S. aureus infection during the subclinical phase of EAE induced a chronic systemic inflammatory response, consisting of increased T- and B-cell counts and systemic production of proinflammatory cytokines. Unexpectedly, the S. aureus infection completely prevented the development of clinical EAE, and markedly reduced inflammatory infiltration and demyelination of the optic nerve, while it increased the number of surviving retinal neurons. Using a S. aureus strain that lacked the extracellular adherence protein (Eap), we determined that the extracellular adherence protein is at least partially responsible for the inhibitory effect of $S$. aureus infection on autoimmune inflammation of the central nervous system.
\end{abstract}

Conclusions: Our results demonstrate for the first time that chronic infection with S. aureus has a beneficial effect on $E A E$, indicating a dual role of infection in the pathogenesis of MS. We also showed that secretion of Eap by S. aureus plays a major role in preventing autoimmune inflammation of the CNS. Moreover, we identified Eap as a factor responsible for this protective effect.

Keywords: Infection, Experimental autoimmune encephalomyelitis, S. aureus, Eap, Neurodegeneration

\section{Background}

Multiple sclerosis (MS) is an autoimmune inflammatory demyelinating disease of the central nervous system (CNS), which often manifests with optic neuritis in its early phase. Although the exact cause of this highly complex disease is still unknown, genetic and environmental factors are thought to be involved in disease initiation and

\footnotetext{
*Correspondence: k.hein@uni-goettingen.de

'Department of Neurology, University Medicine Goettingen,

Robert-Koch-Strasse 40, 37075 Goettingen, Germany

Full list of author information is available at the end of the article
}

pathogenesis [1]. A genome-wide study revealed an overrepresentation of immunologically relevant genes in MS patients [2]. However, the high rate of discordance in monozygotic twins [3] and data from migration studies indicate that environmental factors play an equal or even more important role than genes in the pathogenesis of MS.

Previous experimental and clinical studies demonstrated that bacterial and viral infections can trigger and aggravate autoimmune diseases [4-8]. Paradoxically, some microorganisms seem to prevent MS [9-11]. Thus, there is ongoing

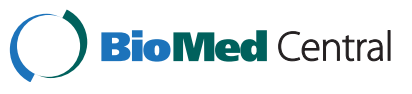

(c) 2015 Kumar et al.; licensee BioMed Central. This is an Open Access article distributed under the terms of the Creative Commons Attribution License (http://creativecommons.org/licenses/by/4.0), which permits unrestricted use, distribution, and reproduction in any medium, provided the original work is properly credited. The Creative Commons Public Domain Dedication waiver (http://creativecommons.org/publicdomain/zero/1.0/) applies to the data made available in this article, unless otherwise stated. 
debate on the dual role of infection in the pathogenesis of MS. Moreover, the underlying biological processes, especially the association of systemic infection and neurodegeneration, a major histopathological correlate of disability in MS patients, are poorly understood. Given the complexity of the interplay between infection and autoimmunity, the majority of the knowledge stems from animal studies in experimental autoimmune encephalomyelitis (EAE), an animal model of MS.

In our present study, we induced EAE by immunization with myelin oligodendrocyte glycoprotein (MOG). Although the extent of spinal cord lesions in this model shows a certain variability, active immunization of female brown Norway (BN) rats with MOG leads to optic neuritis with acute axonal degeneration of the optic nerve $(\mathrm{ON})$ and consecutive apoptosis of retinal ganglion cells (RGCs) in $90 \%$ of the animals [12-15]. Therefore, this EAE model provides a unique tool for investigating the morphological changes in neuronal cell bodies and in axons during neurodegeneration of the optic nerve.

Staphylococcus aureus (S. aureus) is a harmful pathogen in both hospital- and community-associated infections [16]. Locally applied S. aureus in implanted tissue cages have been found to induce persistent chronic systemic infections in animals [17]. In this study, we combined a newly established chronic $S$. aureus infection model with MOG-induced EAE in BN rats to investigate the impact of chronic systemic infection on the clinical course of MS and neurodegeneration in an animal model of MS.

\section{Methods}

\section{Rats}

Female brown Norway rats 8 to 10 weeks of age were used in all experiments. They were obtained from Charles River (Sulzfeld; Germany) and kept under environmentally controlled and pathogen-free conditions. All experiments involving animal use were performed in accordance with the relevant laws and institutional guidelines. These experiments have been approved by the local authorities of Braunschweig, Germany.

\section{Bacterial inoculum preparation}

The S. aureus strains ATCC 29213 (kindly provided by Raimund Lugert from the Department of Microbiology, University of Goettingen; Germany), Newman ATCC 25904 [18] and the extracellular adherence protein (Eap) deficient strain of ATCC 25904, AH12 [19] (kindly provided by Markus Bischoff from the Institute for Medical Microbiology and Hygienie, University of Saarland; Germany) were used in these experiments. A single colony of the respective $S$. aureus strain was inoculated into brain heart infusion medium and incubated for 20 hours at $37^{\circ} \mathrm{C}$ in a shaking incubator. Afterwards, $50 \mu \mathrm{l}$ of the bacterial culture grown for 20 hours were inoculated into $10 \mathrm{ml}$ of fresh brain heart infusion medium and again incubated at $37^{\circ} \mathrm{C}$ in a shaking incubator. Bacteria were harvested after 6 hours of incubation at the time when the bacterial culture reached the log phase of growth. Bacterial concentrations were determined by quantitative plating on blood agar plates, and aliquots were kept at $-80^{\circ} \mathrm{C}$ until further use.

\section{Retrograde labeling of retinal ganglion cells}

Retrograde labeling of retinal ganglion cells (RGCs) and tissue cage implantation was done during a single anesthesia, 2 to 3 weeks prior to MOG immunization. Rats were anesthetized by intraperitoneal injection of ketamine (Ketanest 10; $0.95 \mathrm{ml} / \mathrm{kg}$; Atarost, Twistringen; Germany) and xylazine $2 \%(0.25 \mathrm{ml} / \mathrm{kg}$; Albrecht, Aulendorf; Germany) and positioned in a stereotaxic frame. The skin was incised mediosagittally, and holes were drilled into the skull above each superior colliculus $(6.8 \mathrm{~mm}$ dorsal and $2 \mathrm{~mm}$ lateral from bregma). $2 \mu \mathrm{l}$ of fluorescent dye fluorogold (5\% in distilled water; Fluorochrome, Englewood, $\mathrm{CO}$ ) were injected into both superior colliculi. After that, tissue cage implantation was performed.

\section{Experimental setup and timeline}

Two experiments with a total of 62 animals were carried out (Figure 1). Tissue cage implantation was performed in all animals. Two to three weeks after the tissue cage implantation and retrograde labeling of RGCs, $400 \mu \mathrm{l}$ of $2.3 \%$ semi-solid agar was injected into the tissue cage using a $27 \mathrm{G}$ needle (BD Eclipse, Heidelberg; Germany) in order to enable persistent infection throughout the course of the experiment by providing extra surface area for the growth of bacteria. Before the agar injection, tissue cage fluid (TCF) was obtained percutaneously from all animals and checked for sterility by plating on blood

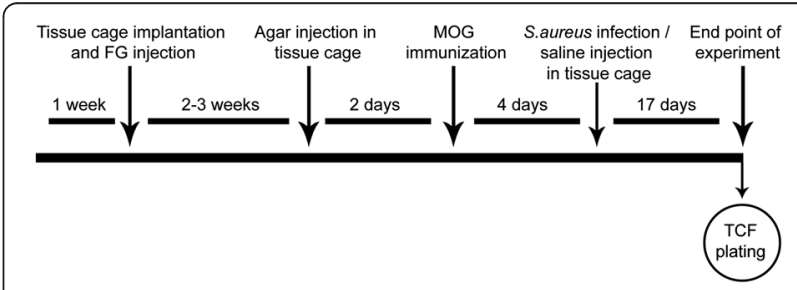

Figure 1 Experimental timeline. Tissue cage (TC) implantation and fluorogold (FG) injection was done 2 to 3 weeks prior to myelin oligodendrocyte glycoprotein (MOG) immunization. Agar was injected into the TC 2 days before immunization. Injection of Staphylococcus aureus (S. aureus) or saline was performed on day 4 postimmunization (pi). Animals were followed until day 8 of experimental autoimmune encephalomyelitis (EAE) or day 21 pi in case of clinically healthy animals. To monitor the infection, blood samples were taken throughout the whole experiment. Tissue was harvested from the optic nerve for histopathological analysis; retina was flat-mounted for quantification of retinal ganglion cells. Tissue cage fluid (TCF) was checked for the presence of bacteria. 
agar plates. Animals were excluded from the experiment if they had contaminated TCF. Two days after the agar injection into the tissue cage, MOG-immunization was done and considered day zero of immunization.

A rapid neurodegeneration occurs already in the preclinical phase of EAE [14], which causes the failure of most of therapeutic interventions, when applied at later time points during the disease course $[15,20]$. Therefore, infection was performed on day 4 postimmunization (pi) to elucidate whether infection modulates the course of EAE and has any influence on the neurodegeneration in this animal model. In the first experiment $(\mathrm{n}=36)$, one animal group was infected with a wild-type strain of $S$. aureus (ATCC 29213). The corresponding control group received saline. To prove our hypothesis of the anti-inflammatory effect of Eap, animals $(n=26)$ were randomized into the three different groups. One group was infected with the wild-type S. aureus strain (ATCC 25904). The second group was infected with the $S$. aureus strain deficient for Eap (AH12). The corresponding control group received saline. Animals were followed until day 8 after clinical manifestation of the disease (EAEd8) or day 21 pi in case of clinically healthy animals. At the end of the experiment, TCF was obtained percutaneously from all (infected and noninfected) animals. TCF was checked for the presence of bacterial colonies by plating on blood agar plates.

\section{Tissue cage preparation and implantation}

Rigid polytetrafluoroethylene (teflon) tissue cages (internal and external diameter of 8 and $10 \mathrm{~mm}$ respectively, length $25 \mathrm{~mm}$ ) perforated by around 100 regularly spaced holes (diameter $1 \mathrm{~mm}$ ) containing two polymethylmethacrylate (PMMA) cover slips per tissue cage, sealed at both ends with a suture (Ethicon, Norderstedt; Germany), were used as a foreign body implant. A cutaneous incision in the left flank was made under anesthesia, and one autoclaved tissue cage was subcutaneously implanted under sterile conditions into each animal.

\section{Induction of chronic infection}

Infection was performed by injection of $200 \mu \mathrm{l}$ of bacterial culture diluted in $0.9 \% \mathrm{NaCl}$ (saline) (B. Braun, Melsungen; Germany) containing $2 \times 10^{7}$ colony forming units (CFU) of the respective $S$. aureus strain into the agar of the tissue cage. Control animals received $200 \mu \mathrm{l}$ saline into their tissue cage.

\section{Induction and evaluation of experimental autoimmune encephalomyelitis}

Rats were anesthetized by inhalation anesthesia with isoflurane (Abbott, Wiesbaden; Germany) and injected intradermally at the base of the tail with a total volume of $200 \mu \mathrm{l}$ inoculum, containing $50 \mu \mathrm{g}$ recombinant rat MOG $^{\text {Igd }}$ (kindly provided by C. Stadelmann,
Institute of Neuropathology, Goettingen; Germany) in saline emulsified (1:1) with complete Freund's adjuvant (CFA; Sigma-Aldrich, St. Louis, MO) containing $200 \mu \mathrm{g}$ heat-inactivated Mycobacterium tuberculosis (strain $\mathrm{H} 37$ RA; Difco Laboratories, Detroit, MI). Rats were scored for clinical signs of EAE and were weighed daily. This score reflects the amount of spinal cord lesions and does not include visual symptoms or correlate with the severity of optic neuritis ([15,21]. The signs were scored as follows: grade 0 , no symptoms; grade 0.5 , distal paresis of the tail; grade 1, complete tail paralysis; grade 1.5, paresis of the tail and mild hind limb paresis; grade 2.0, unilateral severe hind limb paresis; grade 2.5, bilateral severe hind limb paresis; grade 3.0, complete bilateral hind limb paralysis; grade 3.5 , complete bilateral hind limb paralysis and paresis of one front limb; grade 4, complete paralysis (tetraplegia), moribund state, or death.

\section{Leukocyte count}

To monitor the systemic infection leukocytes were counted in the peripheral blood every second day until day 8 after MOG immunization and then at intervals of 3 days until day 20 pi. Blood samples were taken sublingually after inhalation anesthesia with isoflurane. A total of $10 \mu \mathrm{l}$ of blood sample was diluted in $190 \mu \mathrm{l}$ of $4 \%$ glacial acetic acid, and leukocyte counting was performed in a Neubauer-haemocytometer (Superior-Marienfeld, LaudaKönigshofen; Germany).

\section{Western blotting}

For Western blot analysis, 6 animals ( $\mathrm{n}=3$ for each group) were sacrificed on day 3 postinfection. Blood samples were collected by cardiac puncture using $18 \mathrm{G}$ needle (BD Eclipse, Heidelberg; Germany) from S. aureus infected and noninfected animals and placed on ice for 30 minutes. Serum was separated from the whole blood by centrifuging it at 3,500 rpm for 10 minutes, and protein concentration of the serum was measured using BCA assay kits (Thermo Fisher Scientific Inc; U.S.A). Equal amount of protein from each sample was subjected to $12 \%$ SDS-PAGE and transferred onto a nitrocellulose membrane. The membrane was blocked with $5 \%$ nonfat dry milk in Tris-buffered saline containing $0.1 \%$ Tween 20 (TBST) for 1 hour at room temperature. Incubations with rabbit anti-Eap antibody (1:1500; Cat\# ab92982, Abcam; U.K.), was performed overnight at $4^{\circ} \mathrm{C}$. After being washed, the membrane was incubated with a horseradish peroxidase-conjugated appropriate secondary antibody (1:5,000 Jackson Immuno Research Europe; U.K.) in 5\% nonfat dry milk in TBST for 1 hour at room temperature, and immune-reactive proteins were detected using the enhanced chemiluminescence method (ECL; Amersham). Also, $3 \mu \mathrm{g}$ of purified Eap (a gift from Markus Bischoff, University of Saarland, Germany) was used as positive 
control. Ponceau staining was used to confirm equal loading of proteins.

\section{Histopathology and immunohistochemistry}

Retinas were removed for counting of RGCs, and paraformaldehyde-fixed paraffin-embedded optic nerves (ONs) were taken for histopathological evaluation. After perfusion of rats with $4 \%$ PFA, ONs were post-fixed in $4 \%$ PFA for $24 \mathrm{~h}$ and embedded in paraffin. Histological evaluation was performed on $2 \mu \mathrm{m}$ thick slices stained with Luxol Fast Blue to assess demyelination. Photos of vertical sections were taken using an AxioCam MR Microscopy camera (Zeiss, Göttingen; Germany). The images were processed using Zeiss AxioVision 4.2 software to evaluate the demyelinated area as a percentage of the whole ON cross section. Immunohistochemistry was performed on paraffin embedded $\mathrm{ON}$ cross sections representing three different levels of an ON. ED1 macrophages/ activated microglia (AbD Serotec Cat\# MCA341R RRID: AB_2291300), were detected in cross sections using avidin-biotin detection. Spleen sections served as positive control for ED1 staining. ED1 positive cells were evaluated using the following score: 0 , no labeled cells; 1, a few ED1 positive cells (number countable, infiltration of less than $10 \%$ of the ON cross-section area); 2 , infiltration of less than $10 \%$ of the ON cross section area with ED1 positive cells in at least one of the three cross sections of an ON, number of ED1 positive cells not countable; 3 , infiltration of 10 to $50 \%$ of the ON cross section area with labeled ED1 positive cells in at least one of three cross sections of an ON; 4, infiltration of 50 to $80 \%$ area of the ON cross-section area in at least one of the three cross sections of an $\mathrm{ON}$; and 5, infiltration of more than $80 \%$ of the $\mathrm{ON}$ cross section area in at least one of the three cross sections of an $\mathrm{ON}$.

\section{Quantification of T cell infiltrates in optic nerve}

CD3 staining for assessment of infiltration of CD3-positive cells across the blood-brain barrier was performed on $0.5 \mu \mathrm{m}$ thick cross section slices of paraffin-embedded ONs using anti-CD3 antibody (Biozol Cat\# BZL03543 RRID: AB_2313498). CD3-positive cells were detected by biotinavidin detection. Spleen sections served as positive control for CD3 staining. To quantify T-cell infiltrates in the ON, we used tissue studio that is based on Cognition Network Language (Definiens Cognition Network Technology ${ }^{\circ}$, Definiens Developer XD software, Munich; Germany) In brief, CD3-stained sections were scanned using the 3D Histech 250 Flash slide scanner at 200-fold magnification. The area of interest (optic nerve) was first detected from the background by the color spectrum. After segmentation, nuclei and CD3-positive cytoplasm were discriminated. Within each area of interest, the total number of CD3-positive cells was calculated and expressed as cells $/ \mathrm{mm}^{2}$.

\section{Quantification of axonal densities in optic nerve}

To quantify axonal densities in the $\mathrm{ON}, 0.5-\mu \mathrm{m}$ thick cross section slices of ONs were stained by Bielschowsky silver impregnation staining to visualize axonal structures. Automated quantification of axonal densities was performed on high magnification pictures (100x) applying a custom-programmed script in Cognition Network Language based on the Definiens Cognition Network Technology ${ }^{\circ}$ platform (Definiens Developer XD software, Munich; Germany). Briefly, the programmed script first discriminates between tissue and background (no tissue) by spectral difference detection. Subsequently, the area of detected tissue (region of interest, ROI) was calculated and 'axonal structures' within this ROI were detected based on their dark black color. To discriminate between nucleoli of inflammatory cells and axons (which both structures are stained black in Bielschowsky silver impregnation) only black structures without a faint brownstained circumference (nucleus) were further classified as axonal structures. In a next step, multiple axons in direct contact with each other were further split into the corresponding individual axons if the splitting improved the elliptic shape of an axon. Within each area ROI, the total number of axons was calculated. The density of axons in each $\mathrm{ON}$ was measured in at least nine standardized microscopic fields of each ON. The mean axon density was calculated for each $\mathrm{ON}$ and expressed as axons $/ \mathrm{mm}^{2}$.

\section{Quantification of retinal ganglion cell density}

Retinae were dissected, flat-mounted on glass slides, and examined by fluorescence microscopy (Zeiss Axioplan 2) using a DAPI filter (315/395 nm). Retinal ganglion cell densities were determined by counting labeled cells in three areas $\left(62,500 \mu \mathrm{m}^{2}\right.$ each) per retinal quadrant at three different eccentricities of $1 / 6,3 / 6$, and $5 / 6$ of the retinal radius. Cell counts were performed by two independent investigators following a blinded protocol.

\section{Flow cytometry}

Flow cytometry for lymphocyte counting was performed in blood on day 4 pi prior to infection and 2 days after infection at the time when the leukocyte counts reached their peak. In brief, $100 \mu \mathrm{l}$ blood taken sublingually was collected in $250 \mu \mathrm{l}$ of $5 \mathrm{mM}$ EDTA prepared in isotonic PBS. Samples were washed once with PBS, and RBC lysis buffer (0.1 M ammonium chloride in PBS) was added in each sample. Samples were left at $4^{\circ} \mathrm{C}$ for 10 minutes and washed once with PBS. A total of $100 \mu$ of FACS buffer $\left(\mathrm{PBS}+1 \% \mathrm{BSA}+0.1 \% \quad \mathrm{NaN}_{3}\right)$ containing anti-CD45RA (BioLegend Cat\# 202307 RRID: AB_314010) and anti-CD3 (BioLegend Cat\# 201408 RRID: AB_893304) antibodies were added in each samples at a dilution of 1:200. Incubation was done for 45 minutes at $4^{\circ} \mathrm{C}$ in the dark. The cells were washed once with PBS and re-suspended in $200 \mu \mathrm{l}$ of 
FACS buffer prior to flow cytometric analysis. Analysis was performed by four-color flow cytometry using a FACSCalibur and FacScan software (BD; Goettingen; Germany).

\section{Luminex assay}

A Luminex assay kit (Bio-Plex Pro ${ }^{\text {Tw }}$ Rat Cytokine Th1/Th2 Assay \#171-K1002M), containing premixed coupled magnetic beads and detection antibodies for detecting 12 rat cytokines (IL-1 alpha, IL-1 beta, IL-2, IL-4, IL-5, IL-6, IL-10, IL-12, IL-13, TNF-alpha, INF-gamma, GM-CSF) was used for measurement of cytokine concentrations in serum samples collected at the end of the experiment. The total number of animals used in this cytokine assay was 25 ( $\mathrm{n}=11$ infected with wild-type strain of S. aureus (ATCC 25904); $\mathrm{n}=9$ infected with Eap-deficient of $S$. aureus (AH12); $\mathrm{n}=5$ noninfected control). Quantification of cytokines was performed according to the manufacturer's instructions. Measurement was performed by using a Bioplex 200-system based on the Luminex xMAP-technology (Bio-Rad, Hercules, CA, USA). The signal detection occurred using the Bioplex 200-system and the Bioplex Manager Software version 6.0.

\section{Statistical analysis}

Data are presented as means \pm SEM. Student's $t$-test was used to analyze differences between two animal groups. Multiple comparisons were statistically evaluated by one-way ANOVA using Prism 5 (GraphPad Software). Mann-Whitney $U$ test was used for the analysis of the EAE score (SPSS, IBM). A $P$ value of $<0.05$ was considered to be statistically significant.

\section{Results}

\section{Local infection with Staphylococcus aureus leads to} persistent systemic inflammation

To confirm the persistent local infection in the animals, we collected tissue cage fluid (TCF) from all animals under sterile conditions at the end of the experiment and plated the TCF on blood agar plates. TCF obtained from infected animals contained a high number of bacteria (S. aureus), whereas no bacterial growth was observed in TCF from noninfected control animals. Due to the semisolid consistency of TCF, which is probably due to the presence of agar, dilutions for a more exact determination of bacterial numbers were not possible. To ensure that local application of bacteria induced systemic inflammation, leukocytes were counted in peripheral blood samples until day $20 \mathrm{pi}$ (corresponding to day 16 postinfection). Here, we observed that the leukocyte counts in infected animals $(18475 \pm 685 / \mu l ; n=12$; Figure $2 A)$ were significantly elevated 2 days after infection compared to noninfected control animals $(9000 \pm 305 / \mu \mathrm{l} ; \mathrm{n}=11 ; P<0.001$; Figure 2A). Afterwards, leukocyte counts decreased in the infection group, but remained significantly elevated compared to the control group until day $20 \mathrm{pi}(12457 \pm 1219 / \mu \mathrm{l}$ versus $8583 \pm 936 / \mu \mathrm{l}, P=0.03$; Figure $2 \mathrm{~A}$ ).

An anti-inflammatory effect of Eap secreted by S. aureus was demonstrated in chronic infections as well as in autoimmune disease models [22-24]. Therefore, we hypothesized that this protein is responsible for the protective effects of $S$. aureus infection in EAE. To prove our hypothesis, a second set of experiments was performed by including a group of animals infected with a S. aureus strain deficient for Eap. In this experiment, leukocyte counts were significantly elevated two days after infection in the animals infected with the wild-type strain (17236 \pm $742 / \mu \mathrm{l} ; \mathrm{n}=11 ; P<0.001)$ and in the animals infected with the Eap-deficient strain $(18575 \pm 585 / \mu \mathrm{l} ; \mathrm{n}=10 ; P<0.001)$ in contrast to the control group $(9940 \pm 527 / \mu \mathrm{l} ; \mathrm{n}=5)$ (data not shown). We did not observe any significant difference between the leukocyte counts of the two infection groups at any time point during the whole course of the experiment.

\section{Infection with Staphylococcus aureus enhances T- and B-cell counts in peripheral blood}

Flow cytometry was performed to assess the B- and T-cell counts in peripheral blood on day 4 post immunization (pi) (directly prior to infection) and day 6 pi (corresponding to day 2 after the infection). B-cell counts (Figure 2B; $\mathrm{n}=4$ in each group) were significantly increased in the S. aureus-infected group $(67 \pm 10.55 \% ; P=0.002)$ on day 6 pi compared to day 4 pi. In contrast, no significant change in B-cell counts was observed in noninfected animals on day 6 pi compared to day 4 pi. T-cell counts (Figure 2C; $\mathrm{n}=4$ in each group) increased significantly in both groups on day 6 pi compared to day $4 \mathrm{pi}$, however, the increase was more prominent in infected than in noninfected animals ( $117 \pm 19.38 \%$ versus $45 \pm 8.32 \%$; $P=0.013$; Figure 2 C). These results show that infection with $S$. aureus induces both B-cell and T-cell response in peripheral blood.

\section{Infection with Staphylococcus aureus leads to increased concentrations of pro-inflammatory cytokines in the systemic circulation}

Among the 12 cytokines measured by Luminex assay in serum samples collected at the end of the experiment, we observed differences in the levels of IFN-gamma, IL-6 and TNF-alpha. More detailed, levels of IFN-gamma (Figure 3A) was significantly increased in animals infected with the wild-type bacteria $(411.4 \pm 28.37 \mathrm{pg} / \mathrm{ml})$ compared to animals infected with the Eap-deficient strain $(303.9 \pm 39.08 \mathrm{pg} / \mathrm{ml} ; P=0.035)$ and compared to noninfected control animals $(284.9 \pm 46.49 \mathrm{pg} / \mathrm{ml} ; P=0.029)$. Serum levels of IL-6 (Figure 3B) were also significantly elevated in the group infected with the wild-type $S$. aureus bacterium $(926.6 \pm 57.27 \mathrm{pg} / \mathrm{ml})$ compared to 

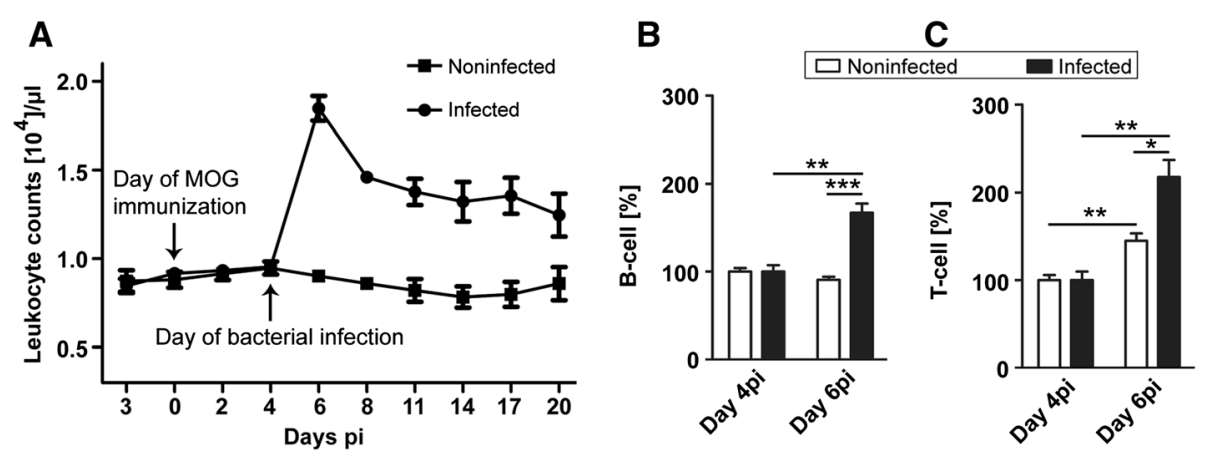

Figure 2 Leukocyte counting and flow cytometry. Leukocyte counts (A) were performed in peripheral blood of infected and noninfected myelin oligodendrocyte glycoprotein (MOG)-immunized animals. The leukocyte count was found to be significantly higher in the infected group. Data are represented as means \pm SEM of all animals from each group $(n=12$, infected; $n=11$, noninfected). Flow cytometry was performed in peripheral blood to assess B- and T-cell populations in animals infected with S. aureus and noninfected control group on day 4 postimmunization (pi) (prior to infection) and on day 6 pi (corresponding to day 2 postinfection). B- (B) and T-cell (C) populations were substantially increased in infected animals 2 days after infection. Data are presented as means \pm SEM. $\left(n=4\right.$ in each group; $\left.{ }^{*} P<0.05 ;{ }^{* *} P<0.01 ;{ }^{* * *} P<0.001\right)$.

the group infected with the Eap-deficient bacterium $(704.4 \pm 75.48 \mathrm{pg} / \mathrm{ml} ; P=0.028)$ and the control group $(668.7 \pm 119.1 \mathrm{pg} / \mathrm{ml} ; P=0.042)$. A tendency towards higher serum levels of TNF-alpha (Figure 3C) was observed in the animals infected with wild-type $S$. aureus bacteria $(330.7 \pm 82.96 \mathrm{pg} / \mathrm{ml})$ compared to the group infected with Eap-deficient $S$. aureus $(233.2 \pm 51.44 \mathrm{pg} / \mathrm{ml}$; $P=0.35)$ and the noninfected control group (169.9 \pm $30.89 \mathrm{pg} / \mathrm{ml} ; P=0.22$ ). The level of other cytokines (IL-1 alpha, IL-1 beta, IL-2, IL-4, IL-5, IL-10, IL-12, IL-13 and GM-CSF) did not change significantly.

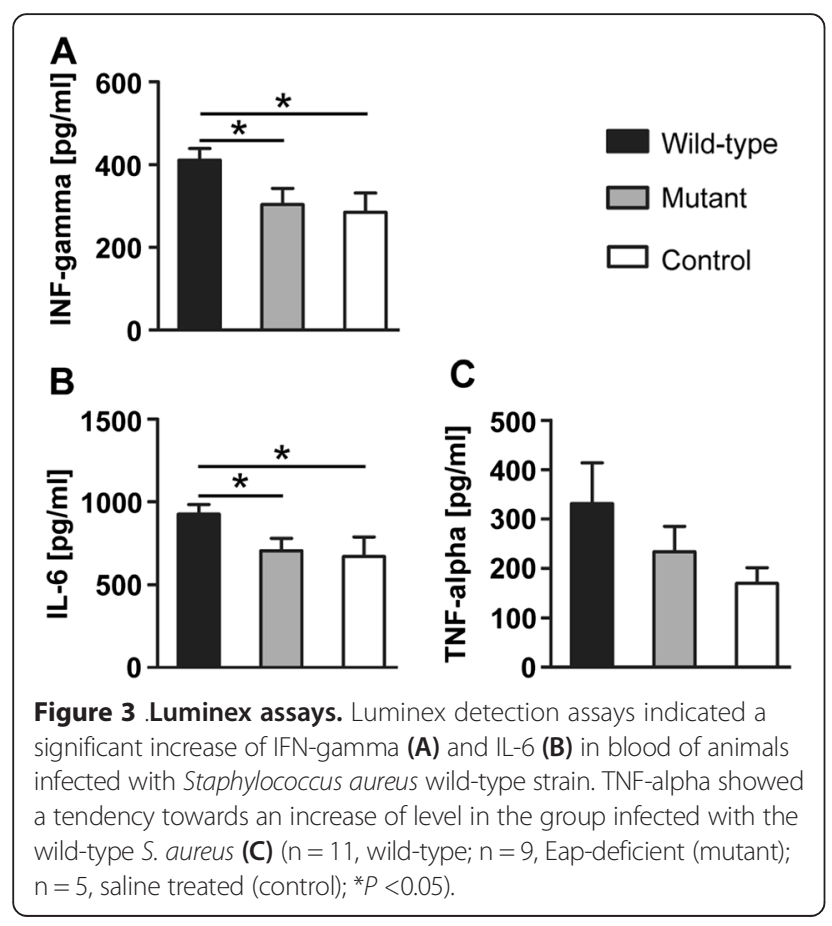

Staphylococcus aureus infection prevents the manifestation of clinical symptoms and suppresses disease activity in myelin oligodendrocyte glycoprotein induced experimental autoimmune encephalomyelitis Animals were infected with $S$. aureus on day 4 after immunization to avoid interference with the initiation of the autoimmune response. Around day 13 after immunization, 6 of the 14 placebo-infected animals developed clinical symptoms while infection with wild-type $S$. aureus (ATCC 29213) prevented the clinical manifestation of EAE in all the infected animals. The mean cumulative score differed significantly between the group infected with $S$. aureus and the respective control group $(P=0.047$; Figure 4). Concerning the clinical manifestation of the disease, a similar result was observed in the experiment in which the Eap-deficient strain and the corresponding wild-type strain were used. Although no clinical signs of EAE were observed in the group infected with $S$. aureus (ATCC 25904) or in the group infected with the Eap-deficient strain (AH12) of S. aureus, animals of the group infected with Eap-deficient $S$. aureus displayed level of histopathological abnormalities (see below). However, noninfected control animals were severely affected with a mean EAE score of $2.4 \pm 0.36(n=5 ; P<0.001$; data not shown here) at the end of the experiment.

\section{Infection with Staphylococcus aureus reduces} neuropathological damage of the optic nerve and increases retinal ganglion cells survival after acute optic neuritis

At day 8 of clinical disease or at day 21 after immunization in the absence of manifest disease, we determined the extent of demyelination of the optic nerves (ONs) by Luxol Fast Blue staining. Additionally, we performed immunohistochemistry for ED1 macrophages/microglia and $\mathrm{CD}^{+}$ T-lymphocytes to assess the extent of inflammatory 


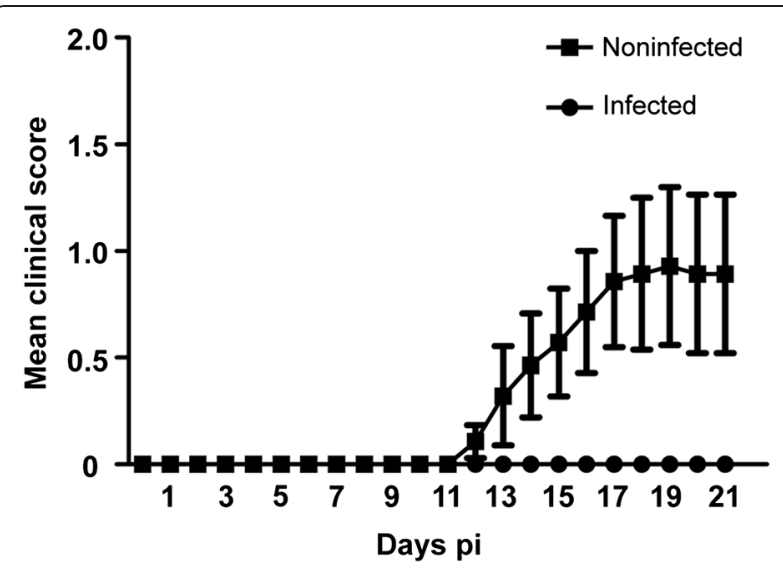

Figure 4 Clinical score. Infection with wild-type Staphylococcus aureus (ATCC 29213) on day 4 postimmunization (pi) prevented disease onset in myelin oligodendrocyte glycoprotein induced experimental autoimmune encephalomyelitis (MOG-EAE). Data represented as means \pm S.E.M. of the daily score. The clinical score represents spinal cord lesions. Presence of optic neuritis is not included ( $n=16$, infected; $n=14$, noninfected).

infiltration. Chronic axonal damage was assessed by Bielschowsky's silver impregnation. For each staining, ON cross sections of three different levels were evaluated.

In the animals infected with the $S$. aureus wild-type strain, we observed significantly less demyelination in ON cross sections (28.08 $\pm 7.94 \%$; Figure $5 \mathrm{~A}, \mathrm{I} ; \mathrm{n}=16)$ compared to noninfected control animals $(67.41 \pm 8.17 \%$; $P=0.0011$; Figure $5 \mathrm{~B}, \mathrm{I} ; \mathrm{n}=14$ ). Analysis of inflammatory infiltrates with ED1 staining revealed a substantially lower infiltration by macrophages and activated microglia in the infected group $(1.22 \pm 0.33$; Figure $5 \mathrm{C}, \mathrm{J} ; \mathrm{n}=16)$ compared to the control group $(3.41 \pm 0.35 ; P<0.001$; Figure 5D, J; $\mathrm{n}=14$ ). Quantification of $\mathrm{CD}^{+}$cells revealed that only the minority of infiltrating cells were $\mathrm{CD}^{+}$T-lymphocytes. At day 21 after immunization, numbers of $\mathrm{CD}^{+}$cells were found to be significantly lower in the $S$. aureus infected group $\left(10.09 \pm 2.88 / \mathrm{mm}^{2}\right.$; Figure $5 \mathrm{E}, \mathrm{K} ; \mathrm{n}=16)$ in comparison to the noninfected control group $\left(34.46 \pm 6.39 / \mathrm{mm}^{2} ; P<0.001\right.$; Figure $5 \mathrm{~F}, \mathrm{~K}$; $\mathrm{n}=14$ ). Using Bielschowky's silver impregnation, we observed a higher axonal density in infected animals (129700 \pm $14580 / \mathrm{mm}^{2}$; Figure 5G, L; $\mathrm{n}=16$ ) compared to noninfected control animals $\left(51260 \pm 12810 / \mathrm{mm}^{2} ; P<0.001\right.$; Figure $5 \mathrm{H}$, $\mathrm{L} ; \mathrm{n}=14)$.

To evaluate the impact of infection on neurodegeneration, numbers of surviving RGCs, the neurons that form the axons of the ON, were counted on day 8 of MOG-EAE. Previously, we have shown that in healthy BN rats shamimmunized with complete Freund's adjuvant (CFA), $2730 \pm$ $145 \mathrm{RGCs} / \mathrm{mm}^{2}$ were detectable (mean \pm SEM; $\mathrm{n}=8$ ) [13]. In our present study, the mean RGC density in noninfected control animals at day 8 of MOG-EAE dropped to $1085 \pm$ $85.7 / \mathrm{mm}^{2}$ (Figure $5 \mathrm{M} ; \mathrm{n}=14$ ). In contrast, RGC density in infected animals was significantly higher $(1449 \pm 64.60$ / $\mathrm{mm}^{2}, P=0.002$; Figure $5 \mathrm{M} ; \mathrm{n}=20$ ). For RGCs counts, $\mathrm{n}$ indicates the number of eyes.

\section{Extracellular adherence protein is present in serum of animals infected with Staphylococcus aureus}

To investigate the presence of Eap in the peripheral blood circulation of infected animals, Western blot analysis was performed in serum samples collected from rats infected with wild-type $S$. aureus as well as from MOG-immunized noninfected control animals. Western blot analysis revealed the presence of Eap in the circulation of the animals infected with S. aureus (Figure 6). No Eap was detected in the serum samples collected from the MOG-immunized noninfected control animals (Figure 6).

\section{The protective effect of wild-type Staphylococcus aureus infection on optic neuritis is reduced in the group infected with respective extracellular adherence protein-deficient strain}

In further experiments, an Eap-deficient $S$. aureus strain and the respective wild-type $S$. aureus strain were used for infection of the animals. In these experiments, we observed significantly less demyelination (Figure 7A) in wild-type $S$. aureus infected animals $(22.77 \pm 8.46 \%$; $\mathrm{n}=11)$ in comparison to both Eap-deficient infected (53.53 \pm $10.56 \% ; P=0.027 ; \mathrm{n}=10)$ and control animals $(100 \pm$ $0 \% ; P<0.001 ; \mathrm{n}=4)$. Accordingly, the extent of inflammation accessed by ED1 staining (Figure $7 \mathrm{~B}$ ) was significantly lower in the group infected with wild-type $S$. aureus bacteria $(1.24 \pm 0.39 ; \mathrm{n}=11)$ in comparison to the group infected with Eap-deficient bacteria $(2.73 \pm 0.40 ; P=0.012$; $\mathrm{n}=10)$ and the noninfected control group $(4.66 \pm 0.15$; $P<0.001 ; \mathrm{n}=4) . \mathrm{CD}^{+}$T-Lymphocyte counts revealed significantly lower numbers of $\mathrm{CD}^{+}$cells (Figure 7C) in animals infected with wild-type $S$. aureus $(7.6 \pm 3.75$ / $\left.\mathrm{mm}^{2} ; \mathrm{n}=11\right)$ in comparison to the animals infected with Eap-deficient bacteria $\left(39.81 \pm 10.37 / \mathrm{mm}^{2} ; P=0.004 ; \mathrm{n}=\right.$ $10)$ and the control group $\left(55.2 \pm 25.8 / \mathrm{mm}^{2} ; P=0.007\right.$; $\mathrm{n}=4$ ). No significant difference was observed in $\mathrm{CD}^{+}$ cell counts between the animals infected with Eapdeficient $S$. aureus bacteria and the noninfected control group $(P=0.5)$. Bielschowsky's silver impregnation was performed to assess the axonal pathology of the optic nerve (Figure 7D) and revealed that the animals infected with wild-type bacteria showed a higher number of axonal counts $\left(173500 \pm 18220 / \mathrm{mm}^{2} ; \mathrm{n}=11\right)$ in comparison to the group infected with Eap-deficient bacteria (73953 \pm $\left.14500 / \mathrm{mm}^{2} ; P<0.001 ; \mathrm{n}=10\right)$ and noninfected control animals $\left(16670 \pm 1938 / \mathrm{mm}^{2} ; P<0.001 ; \mathrm{n}=4\right)$. The RGC density was higher in the animal group infected with the wild-type strain $\left(1447 \pm 66 / \mathrm{mm}^{2}\right.$; Figure $\left.7 E ; n=18\right)$ compared to animals infected with the Eap-deficient strain $\left(1001 \pm 65 / \mathrm{mm}^{2} ; P<0.001\right.$; Figure $\left.7 \mathrm{E} ; \mathrm{n}=13\right)$ and 


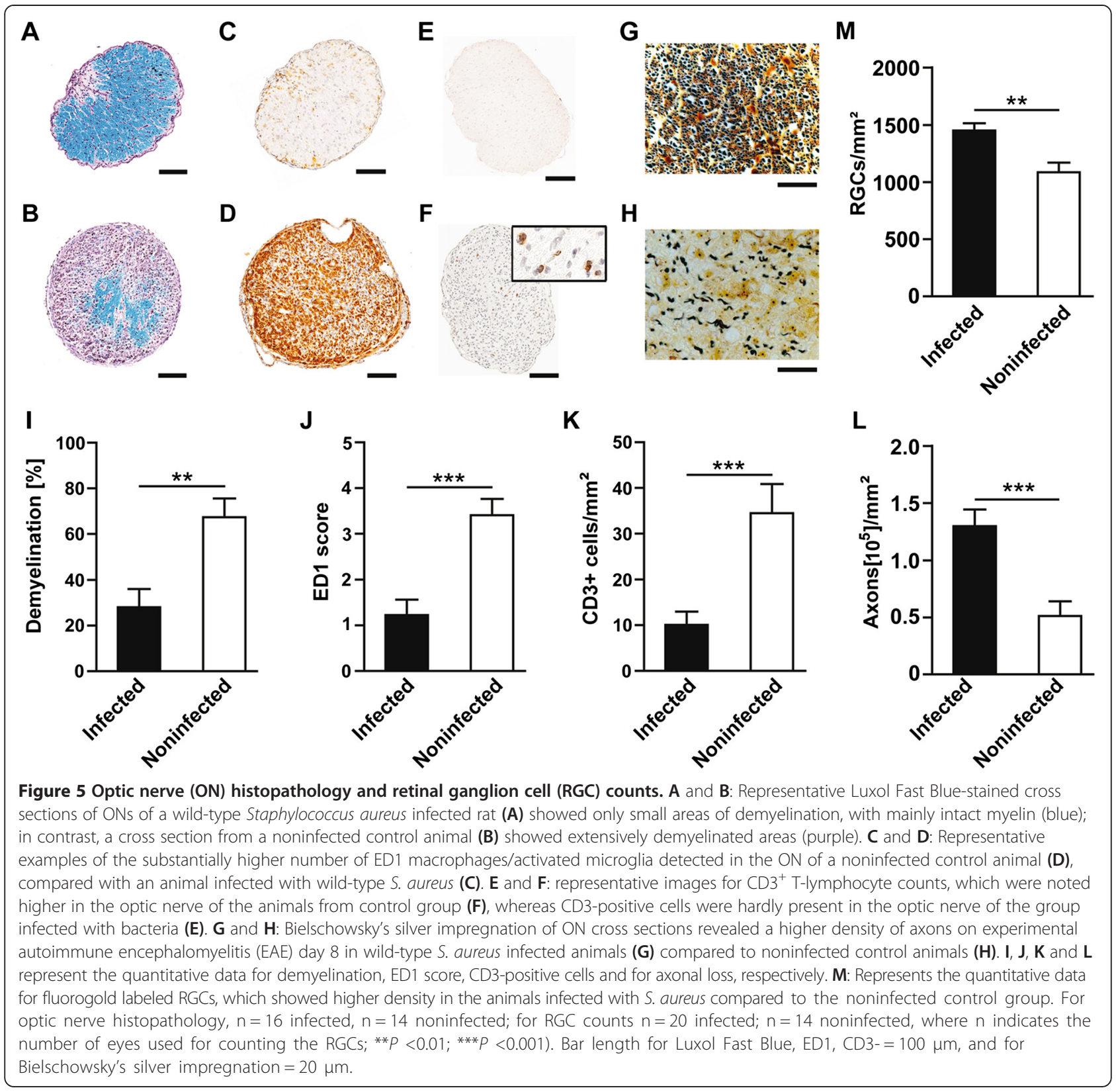

the noninfected control group $\left(810 \pm 52 / \mathrm{mm}^{2}, P<0.001\right.$; Figure 7E; $n=9$ ).

\section{Discussion}

Using a rat model of MOG-induced EAE, we have demonstrated for the first time that chronic infection with $S$. aureus prevents the onset of EAE and reduces the development of histopathologic changes in the optic nerve. Using an extracellular adherence protein (Eap)-deficient strain of $S$. aureus, we showed that secretion of Eap by $S$. aureus plays a major role in preventing inflammation of the central nervous system (CNS).
Peripheral infection has been shown to exacerbate the immune response in experimental models of MS and in patients [7,25-28]. However, investigations of the role of infection in MS patients are complicated by the lack of a surrogate marker of disease activity. The results of magnetic resonance imaging (MRI) studies on the influence of peripheral infection on the number of contrast-enhancing MS lesions as a marker of disease activity are inconsistent [26,29]. Moreover, reliable markers to assess neurodegeneration in MS patients do not exist. For these reasons, much of the knowledge regarding the relationship between systemic infection and autoimmunity in MS is derived from EAE model studies. 


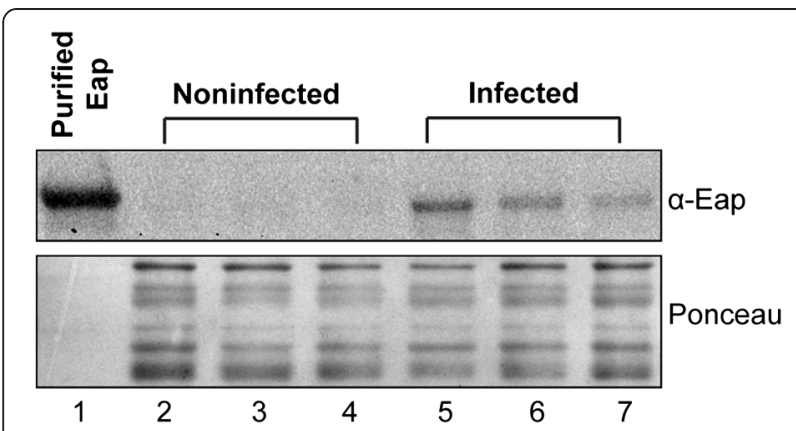

Figure 6 Western blot analysis. Western blot analysis showed the presence of extracellular adherence protein (Eap) in the serum of animals infected with wild-type S. aureus bacterium (Lane 5, 6 and 7) No Eap was detected in the serum samples of the control animals (Lane 2, 3 and 4). Purified Eap (Lane 1) was used as a positive control. Ponceau staining was used as a loading control.

Previous EAE model studies have focused on analyzing the clinical course of the disease. These studies used bacterial compounds (for example, LPS, enterotoxins) [30-32] rather than whole viable bacteria; thus, their results do not accurately reflect the clinical situation of MS patients. To our knowledge, this study is the first to investigate the effects of chronic infection with viable bacteria in an EAE model. By locally injecting a $S$. aureus strain, which is pathogenic for humans, into a previously implanted tissue cage, we established a stable chronic systemic infection in $\mathrm{BN}$ rats. This infection model is advantageous because it induces a mild infection that does not require antibiotic treatment to keep the animals alive. In our study, two days after the local application of the bacteria, corresponding to day 6 after immunization, the systemic infection became prominent as determined by increased leukocyte counts in peripheral blood. The rationale for the selected infection time point came from experimental and clinical studies suggesting that the subclinical phase of MS is the 'at risk' period with the greatest susceptibility to systemic inflammation $[7,33]$.

Infectious agents are known to rapidly expand the pool of immune cells, including auto-reactive T-cells in EAE and thus can contribute to the disease progression $[5,34,35]$. In our study, we detected a substantial increase of B- and T-cell counts in peripheral blood 2 days after the inoculation of bacteria into tissue cages implanted in the animals. Moreover, significant elevation of IL-6 and INF-gamma levels and a tendency to higher levels of TNF-alpha in serum was observed after infection with the $S$. aureus wild-type strains at the end of the experiment. However, at this time point the proinflammatory cytokine pattern was not detected in animals that were infected with the Eap-deficient strain compared to the control. Intriguingly, in spite of ongoing inflammation in the periphery the infection with $S$. aureus prevented the onset of clinical EAE symptoms and decreased the severity of autoimmune optic neuritis.

The entry of leukocytes into the CNS is considered an early phenomenon in MS that induces blood-brain barrier breakdown and neuroinflammation. The relevance of vascular cell adhesion molecule 1 (VCAM-1) and intercellular adhesion molecule (ICAM-1) for migration of lymphocytes across the blood-brain barrier during EAE has been shown in several experimental studies [36-38]. Although the very late antigen- 4 and vascular cell adhesion molecule 1 (VLA-4-VCAM-1) interaction predominantly mediates the initial adhesion to the vessels, lymphocyte functionassociated antigen 1 and intracellular adhesion molecule-1
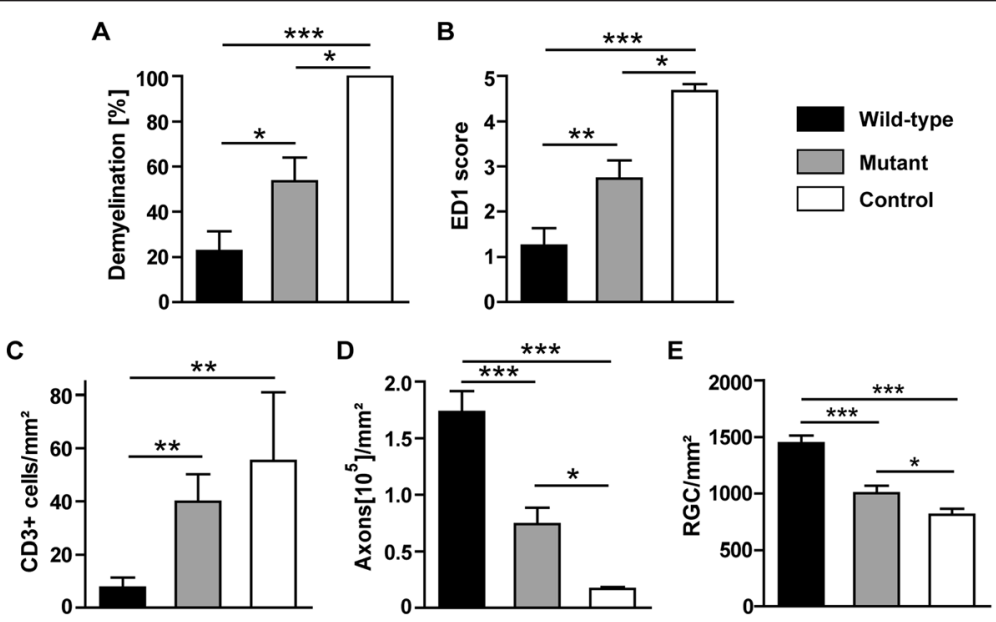

Figure 7 Optic nerve (ON) histopathology and retinal ganglion cell (RGC) counts. The positive effect of $S$. aureus on optic neuritis was reverted in the Eap-deficient strain. Quantitative data for extent of demyelination (A), inflammation (B, C), axonal damage (D) and RGC counts (E). Animals infected with the wild-type strain of $S$. aureus (wild-type; $n=11$ ), with the Eap deficient strain (mutant; $n=10$ ) or treated with saline (control; $n=4)$; while for RGC counts ( $n=18$, wild-type; $n=13$, mutant; $n=9$, control), $n$ indicates the number of eyes used for counting the RGCS), $\left({ }^{*} P<0.05 ;{ }^{* *} P<0.01 ;{ }^{* *} P<0.001\right)$. 
(LFA-1-ICAM-1) are involved in the subsequent transendothelial migration of T-cells $[39,40]$.

S. aureus expresses anti-adhesive and antimigratory factors that specifically interfere with every step of host inflammatory cell recruitment [41]. A major anti-adhesive protein of the $S$. aureus 'secretable expanded repertoire adhesive molecules' (SERAM) is Eap, which is present in 97\% of clinical isolates [42]. Eap interacts specifically with endothelial ICAM-1, leading to inhibition of the ICAM-1integrin interaction [22]. The anti-inflammatory property of Eap in autoimmune diseases has been found in EAE and an animal model of psoriasis $[24,40]$. These observations led us to hypothesize that the anti-inflammatory effects of $S$. aureus infection in MOG-induced EAE are mediated through Eap secretion. In our study, infection with an Eap-deficient $S$. aureus strain led to increased inflammation, demyelination, and axonal damage in the optic nerve when compared to animals infected with wildtype $S$. aureus. However, histopathological analysis of the optic nerve revealed that the anti-inflammatory property of $S$. aureus infection was not completely abolished by the lack of Eap. Moreover, the infection with the Eap-deficient strain prevented the clinical manifestation of the disease indicating that additional factors, such as enterotoxins secreted by bacteria might be involved in the antiinflammatory effects of $S$. aureus. However, the dual role of these enterotoxins has been observed in previous EAE-studies [30,43-45].

Given the importance of ICAM-1 antagonism in different autoimmune diseases [46], Eap is believed to be the most potent factor for inhibition of T-cell migration into the CNS. This hypothesis is supported by our histopathological evaluations, which revealed a substantial reduction in the number of lymphocytes in inflammatory infiltrates obtained from the optic nerves of wild-type $S$. aureus-infected animals. In our previous EAE studies, we observed that a strong anti-inflammatory response is not always sufficient to prevent neurodegeneration [12,15,47]. Although the increased neuronal and axonal survivals detected in S. aureus-infected animals seemed to be related to the anti-inflammatory properties of Eap, we cannot rule out the possibility of direct neuroprotection by Eap. Further studies are needed to clarify this issue.

Approval of immunosuppressive drugs for MS treatment has progressed very rapidly in recent years. Thus, the incidence of infections in MS patients and the problems associated with them are increasing. Our results demonstrate, for the first time, that chronic $S$. aureus infection has beneficial effects on EAE. Importantly, our results do not trivialize the necessity for antibiotic treatment of infections. As infections activate peripheral inflammatory events, they can induce a general immune response in MS patients known as 'sickness behavior'. However, some factors released by bacteria seem to have a beneficial effect on autoimmune inflammation in the CNS.

\section{Conclusions}

Bacterial infections have been assumed to worsen MS disease symptoms and to lead to increased neurodegeneration. In contrast, our results demonstrate for the first time that chronic infection with S. aureus induces strong peripheral systemic inflammation, but still prevented clinical symptoms in an animal model of MS. Moreover, $S$. aureus infection reduced autoimmune inflammation of the CNS and reduced the severity of autoimmune optic neuritis. Furthermore, using an Eap-deficient $S$. aureus strain, we showed that secretion of Eap by $S$. aureus plays a major role in preventing autoimmune inflammation of the CNS. Infection with S. aureus also increased the number of surviving retinal ganglion cells and their axonal counts, most likely via the anti-inflammatory properties of Eap. However, further studies are needed to determine whether Eap exerts a direct neuroprotective effect.

\section{Abbreviations}

ATCC: American type culture collection; BSA: bovine serum albumin;

CD: cluster of differentiation; CFU: colony-forming unit; CNS: central nervous system; EAE: experimental autoimmune encephalomyelitis; Eap: extracellular adherence protein; EDTA: ethylenediaminetetraacetic acid; FG: fluorogold; FACS: fluorescence-activated cell sorting; ICAM-1: intracellular adhesion molecule-1; LFA-1: lymphocyte function-associated antigen 1; MOG: myelin oligodendrocyte glycoprotein; MS: multiple sclerosis; ON: optic nerve; PBS: phosphate buffered saline; Pi: postimmunization; RBC: red blood cells; RGCs: retinal ganglion cells; S. aureus: Staphylococcus aureus; TCF: tissue cage fluid.

Competing interests

The authors declare that they have no competing interests.

\section{Authors' contributions}

$\mathrm{KH}, \mathrm{MB}, \mathrm{RN}, \mathrm{PK}$, and $\mathrm{BK}$ contributed to the conception and design. PK, MK $\mathrm{BK}$, and $\mathrm{SH}$ contributed to the acquisition of data. $\mathrm{KH}, \mathrm{PK}, \mathrm{MB}, \mathrm{SH}, \mathrm{SS}$, and RN contributed to the analysis and the editing of the data. BK, SH, RN, SS, PK, $M B, K H$ drafted and/or revised the article. All authors read and approved the version submitted for publication.

\section{Acknowledgements}

This work was supported by the Else Kröner-Fresenius-Stiftung. KH was funded by the Medical Faculty of the University of Goettingen; Germany. PK was (partly) supported by the Goettingen Graduate School for Neurosciences und Molecular Biosciences (DFG Grant GSC226/2). We thank Irina Graf, Doron Merkler, Dimitri Lodygin and Matthias Schmitz for expert technical assistance. We also thank to Markus Bischoff to provide us with the bacterial strain and purified Eap.

\section{Author details}

${ }^{1}$ Department of Neurology, University Medicine Goettingen, Robert-Koch-Strasse 40, 37075 Goettingen, Germany. ${ }^{2}$ Institute of Neuropathology, University Medicine Goettingen, Goettingen 37075, Germany. ${ }^{3}$ Department of Pathology and Immunology, Centre Médical Universitaire 1, Rue Michel-Servet 1211, Geneva 4, Switzerland.

Received: 12 September 2014 Accepted: 10 January 2015 Published online: 03 February 2015

\section{References}

1. Gourraud PA, Harbo HF, Hauser SL, Baranzini SE. The genetics of multiple sclerosis: an up-to-date review. Immunol Rev. 2012;248:87-103. 
2. Craig DW, Goor RM, Wang Z, Paschall J, Ostell J, Feolo M, et al. Assessing and managing risk when sharing aggregate genetic variant data. Nat Rev Genet. 2011;12:730-6.

3. Willer CJ, Dyment DA, Risch NJ, Sadovnick AD, Ebers GC. Twin concordance and sibling recurrence rates in multiple sclerosis. Proc Natl Acad Sci U S A. 2003;100:12877-82.

4. Andersen $\mathrm{O}$, Lygner PE, Bergstrom T, Andersson M, Vahlne A. Viral infections trigger multiple sclerosis relapses: a prospective seroepidemiological study. J Neurol. 1993;240:417-22.

5. Du C, Yao SY, Ljunggren-Rose A, Sriram S. Chlamydia pneumoniae infection of the central nervous system worsens experimental allergic encephalitis. J Exp Med. 2002;196:1639-44.

6. Munger KL, Peeling RW, Hernan MA, Chasan-Taber L, Olek MJ, Hankinson SE, et al. Infection with Chlamydia pneumoniae and risk of multiple sclerosis. Epidemiology. 2003;14:141-7

7. Herrmann I, Kellert M, Schmidt H, Mildner A, Hanisch UK, Bruck W, et al. Streptococcus pneumoniae Infection aggravates experimental autoimmune encephalomyelitis via Toll-like receptor 2. Infect Immun. 2006;74:4841-8.

8. Lee YK, Menezes JS, Umesaki Y, Mazmanian SK. Proinflammatory T-cell responses to gut microbiota promote experimental autoimmune encephalomyelitis. Proc Natl Acad Sci U S A. 2011;108 Suppl 1:4615-22.

9. Lehmann D, Ben-Nun A. Bacterial agents protect against autoimmune disease. I. Mice pre-exposed to Bordetella pertussis or Mycobacterium tuberculosis are highly refractory to induction of experimental autoimmune encephalomyelitis. J Autoimmun. 1992;5:675-90.

10. Franca TG, Chiuso-Minicucci F, Zorzella-Pezavento SF, Ishikawa LL, da Rosa LC, Colavite PM, et al. Previous infection with Staphylococcus aureus strains attenuated experimental encephalomyelitis. BMC Neurosci. 2014;15:8.

11. Ascherio A, Munger KL. Environmental risk factors for multiple sclerosis. Part I: the role of infection. Ann Neurol. 2007;61:288-99.

12. Rau CR, Hein K, Sattler MB, Kretzschmar B, Hillgruber C, McRae BL, et al. Anti-inflammatory effects of FTY720 do not prevent neuronal cell loss in a rat model of optic neuritis. Am J Pathol. 2011;178:1770-81.

13. Meyer R, Weissert R, Diem R, Storch MK, de Graaf KL, Kramer B, et al. Acute neuronal apoptosis in a rat model of multiple sclerosis. J Neurosci. 2001;21:6214-20

14. Hobom M, Storch MK, Weissert R, Maier K, Radhakrishnan A, Kramer B, et al. Mechanisms and time course of neuronal degeneration in experimental autoimmune encephalomyelitis. Brain Pathol. 2004;14:148-57.

15. Maier K, Kuhnert AV, Taheri N, Sattler MB, Storch MK, Williams SK, et al. Effects of glatiramer acetate and interferon-beta on neurodegeneration in a model of multiple sclerosis: a comparative study. Am J Pathol. 2006;169:1353-64

16. Grady $M$, Cullen JJ. Preventing postoperative Staphylococcus infections: an update. Surg Technol Int. 2003;11:57-60.

17. Lucet JC, Herrmann M, Rohner P, Auckenthaler R, Waldvogel FA, Lew DP. Treatment of experimental foreign body infection caused by methicillin-resistant Staphylococcus aureus. Antimicrob Agents Chemother. 1990;34:2312-7.

18. Duthie ES, Lorenz LL. Staphylococcal coagulase; mode of action and antigenicity. J Gen Microbiol. 1952;6:95-107.

19. Hussain $M$, von Eiff $C$, Sinha B, Joost I, Herrmann M, Peters $G$, et al. Eap Gene as novel target for specific identification of Staphylococcus aureus. J Clin Microbiol. 2008:46:470-6.

20. Maier K, Merkler D, Gerber J, Taheri N, Kuhnert AV, Williams SK, et al. Multiple neuroprotective mechanisms of minocycline in autoimmune CNS inflammation. Neurobiol Dis. 2007;25:514-25.

21. Storch MK, Stefferl A, Brehm U, Weissert R, Wallstrom E, Kerschensteiner M, et al. Autoimmunity to myelin oligodendrocyte glycoprotein in rats mimics the spectrum of multiple sclerosis pathology. Brain Pathol. 1998:8:681-94

22. Chavakis T, Hussain M, Kanse SM, Peters G, Bretzel RG, Flock Jl, et al. Staphylococcus aureus extracellular adherence protein serves as antiinflammatory factor by inhibiting the recruitment of host leukocytes. Nat Med. 2002;8:687-93.

23. Lee LY, Miyamoto YJ, Mclntyre BW, Hook M, McCrea KW, McDevitt D, et al. The Staphylococcus aureus Map protein is an immunomodulator that interferes with T cell-mediated responses. J Clin Invest. 2002;110:1461-71.

24. Wang H, von Rohrscheidt J, Roehrbein J, Peters T, Sindrilaru A, Kess D, et al. Extracellular adherence protein of Staphylococcus aureus suppresses disease by inhibiting T-cell recruitment in a mouse model of psoriasis. J Invest Dermatol. 2010;130:743-54.
25. Rapp NS, Gilroy J, Lerner AM. Role of bacterial infection in exacerbation of multiple sclerosis. Am J Phys Med Rehabil. 1995;74:415-8.

26. Edwards S, Zvartau M, Clarke H, Irving W, Blumhardt LD. Clinical relapses and disease activity on magnetic resonance imaging associated with viral upper respiratory tract infections in multiple sclerosis. J Neurol Neurosurg Psychiatry. 1998;64:736-41.

27. Buljevac D, Flach HZ, Hop WC, Hijdra D, Laman JD, Savelkoul HF, et al. Prospective study on the relationship between infections and multiple sclerosis exacerbations. Brain. 2002;125:952-60.

28. Buljevac D, Hop WC, Reedeker W, Janssens AC, van der Meche FG, van Doorn PA, et al. Self reported stressful life events and exacerbations in multiple sclerosis: prospective study. BMJ. 2003;327:646

29. Kalkers NF, Vrenken H, Uitdehaag BM, Polman CH, Barkhof F. Brain atrophy in multiple sclerosis: impact of lesions and of damage of whole brain tissue. Mult Scler. 2002;8:410-4.

30. Schiffenbauer J, Johnson HM, Butfiloski EJ, Wegrzyn L, Soos JM. Staphylococcal enterotoxins can reactivate experimental allergic encephalomyelitis. Proc Natl Acad Sci U S A. 1993;90:8543-6.

31. Soos JM, Hobeika AC, Butfiloski EJ, Schiffenbauer J, Johnson HM. Accelerated induction of experimental allergic encephalomyelitis in PL/J mice by a non-V beta 8-specific superantigen. Proc Natl Acad Sci U S A. 1995;92:6082-6.

32. Moreno B, Jukes JP, Vergara-Irigaray $N$, Errea O, Villoslada P, Perry VH, et al Systemic inflammation induces axon injury during brain inflammation. Ann Neurol. 2011;70:932-42.

33. Sibley WA, Bamford CR, Clark K. Clinical viral infections and multiple sclerosis. Lancet. 1985;1:1313-5.

34. Nogai A, Siffrin V, Bonhagen K, Pfueller CF, Hohnstein T, Volkmer-Engert R, et al. Lipopolysaccharide injection induces relapses of experimental autoimmune encephalomyelitis in nontransgenic mice via bystander activation of autoreactive CD4+ cells. J Immunol. 2005;175:959-66.

35. Visser L. Jan de Heer H, Boven LA, van Riel D, van Meurs M, Melief MJ, et al. Proinflammatory bacterial peptidoglycan as a cofactor for the development of central nervous system autoimmune disease J Immunol. 2005;174:808-16.

36. Yednock TA, Cannon C, Fritz LC, Sanchez-Madrid F, Steinman L, Karin N. Prevention of experimental autoimmune encephalomyelitis by antibodies against alpha 4 beta 1 integrin. Nature. 1992;356:63-6.

37. Archelos JJ, Jung S, Maurer M, Schmied M, Lassmann H, Tamatani T, et al. Inhibition of experimental autoimmune encephalomyelitis by an antibody to the intercellular adhesion molecule ICAM-1. Ann Neurol. 1993;34:145-54.

38. Gordon EJ, Myers KJ, Dougherty JP, Rosen H, Ron Y. Both anti-CD11a (LFA-1) and anti-CD11b (MAC-1) therapy delay the onset and diminish the severity of experimental autoimmune encephalomyelitis. J Neuroimmunol. 1995;62:153-60.

39. Laschinger M, Vajkoczy P, Engelhardt B. Encephalitogenic T cells use LFA-1 for transendothelial migration but not during capture and initial adhesion strengthening in healthy spinal cord microvessels in vivo. Eur J Immunol. 2002;32:3598-606.

40. Xie C, Alcaide P, Geisbrecht BV, Schneider D, Herrmann M, Preissner KT, et al. Suppression of experimental autoimmune encephalomyelitis by extracellular adherence protein of Staphylococcus aureus. J Exp Med. 2006;203:985-94

41. Chavakis T, Preissner KT, Herrmann M. The anti-inflammatory activities of Staphylococcus aureus. Trends Immunol. 2007:28:408-18.

42. Harraghy N, Hussain M, Haggar A, Chavakis T, Sinha B, Herrmann M, et al. The adhesive and immunomodulating properties of the multifunctional Staphylococcus aureus protein Eap. Microbiology. 2003;149:2701-7.

43. Kalman B, Lublin FD, Lattime E, Joseph J, Knobler RL. Effects of staphylococcal enterotoxin $B$ on $T$ cell receptor $V$ beta utilization and clinical manifestations of experimental allergic encephalomyelitis. J Neuroimmunol. 1993;45:83-8.

44. Soos JM, Schiffenbauer J, Johnson HM. Treatment of PL/J mice with the superantigen, staphylococcal enterotoxin B, prevents development of experimental allergic encephalomyelitis. J Neuroimmunol. 1993;43:39-43.

45. Matsumoto Y, Fujiwara M. Immunomodulation of experimental autoimmune encephalomyelitis by staphylococcal enterotoxin D. Cell Immunol. 1993;149:268-78.

46. Kaneider NC, Leger AJ, Kuliopulos A. Therapeutic targeting of molecules involved in leukocyte-endothelial cell interactions. FEBS J. 2006;273:4416-24.

47. Diem R, Hobom M, Maier K, Weissert R, Storch MK, Meyer R, et al. Methylprednisolone increases neuronal apoptosis during autoimmune CNS inflammation by inhibition of an endogenous neuroprotective pathway. J Neurosci. 2003:23:6993-7000. 